\title{
Correlation Analysis Between Antioxidant Activity and Phytochemicals in Korean Colored Corns Using Principal Component Analysis
}

\author{
Kang Mo Ku${ }^{1}$, Hye Suk Kim ${ }^{1}$, Soon Kwon Kim ${ }^{2}$ \& Young-Hwa Kang ${ }^{1}$ \\ ${ }^{1}$ Department of Horticulture, College of Agriculture \& Life Sciences, Kyungpook National University, Daegu, \\ Korea \\ ${ }^{2}$ Department of Agronomy, College of Agriculture \& Life Sciences, Kyungpook National University, Daegu, \\ Korea \\ Correspondence: Young-Hwa Kang, Department of Horticulture, College of Agriculture \& Life Sciences, \\ Kyungpook National University, Daegu, Korea. Email: youngh@knu.ac.kr
}

Received: January 10, 2014 Accepted: January 23, 2014 Online Published: March 15, 2014

doi:10.5539/jas.v6n4p1 URL: http://dx.doi.org/10.5539/jas.v6n4p1

\begin{abstract}
The colored corns are used as food as well as for feed in Asian countries; however, the active component of antioxidant activity in Korean colored corns has not been investigated. Thus, we measured the total content of carotenoids, phenols, flavonoids, and anthocyanins from 40 Korean colored corn genotypes for correlation analysis between antioxidant activity and these phytochemicals. The ferric reducing ability power (FRAP) and 2,2'-azinobis (3-ethylbenzothiazoline-6-sulfonic acid) diammonium salt (ABTS) activity were measured in order to study this correlation. As a result, there was large variation in total anthocyanin (coefficient of variation, $\mathrm{CV}$ 85.0\%) and total carotenoid contents (CV 87.8\%), while CVs of total phenol, total flavonoid contents, ABTS and FRAP was relatively low (CV $15.0 \%, 22.8 \%, 15.5 \%$, and $16.3 \%$ respectively). There were meaningful correlations between ABTS and anthocyanins, phenols, and flavonoids, as well as correlations between FRAP and phenols as well as FRAP and flavonoids. We also obtained a more informative and easily visualized result by using principal component analysis (PCA). Anthocyanins and carotenoids showed a large variation as compared to other compounds. Anthocyanins are a good target to increase antioxidant activity in colored corns.
\end{abstract}

Keywords: corn, ABTS, FRAP, antioxidant, phenolics, flavonoids

\section{Introduction}

Corn is widely considered an important crop across the world. It is not only an important staple food, but also an outstanding feed for livestock, offering high energy, a low amount of fiber and high digestibility. According to Liu (2007), corn contains the highest antioxidant activity among selected crops and has significant total phenol content. Corn contains various antioxidant compounds such as anthocyanins, carotenoids, phenols, and flavonoids. Anthocyanins are responsible for the purple or red color in corn. Previous studies have revealed antimutagenic, antioxidant, and cancer chemopreventive properties of colored corn (Lopez-Martinez, Parkin, \& Garcia, 2011; Mendoza-Díaz et al., 2012; Pedreschi \& Cisneros-Zevallos, 2006). Carotenoids are the precursor of vitamin A that can be converted to retinal. They absorb damaging blue and ultraviolet light and also act as antioxidants. Polyphenol and flavonoids are closely related with chemopreventive activity as ROS scavengers (K. W. Lee \& H. J. Lee, 2006; Moon, Wang, \& Morris, 2006). Reactive oxygen species (ROS) are involved in mediating various pathological processes including cancer, aging, and atherosclerosis (Valko, Izakovic, Mazur, Rhodes, \& Telser, 2004). Reducing the chance of chronic diseases can be achieved by scavenging ROS. Several studies have shown that an increased dietary intake of polyphenol and flavonoids correlates with reduced oxidative stress, inflammation, tumor, and coronary heart disease (Laranjinha, Almeida, \& Madeira, 1994; Moon, Wang, \& Morris, 2006; Poulsen, Prieme, \& Loft, 1998)

Corn could be a good source of antioxidants for daily consumption considering its high polyphenol content, but it has not received much attention. There were a few studies on the antioxidant activity of corn which have looked at genotype (Li, Wei, White, \& Beta, 2007; Lopez-Martinez et al., 2011), heat process (Dewanto, Wu, \& Liu, 2002; Lopez-Martinez et al., 2011), and maturity effect (Xu et al., 2010). It is important to study what the most important 
antioxidant compounds in corn are and their variations. From a practical perspective, such information can be applied in order to breed better corns that contain compounds which promote the health of consumers.

Unlike sweet corn which is popular as a food in most western countries, colored waxy corn has been eaten for a long time in South American and some Asian countries, such as China and Korea. As such, various colored waxy corns are available in the Korean market, such as purple, red, blue, and bicolor purple and yellow (composite of purple waxy and dent). The variation of antioxidant compounds of Korean purple corn has not yet been investigated, although there have been several intensive studies on colored corn from the South American region (Cevallos-Casals \& Cisneros-Zevallos, 2004; Lopez-Martinez et al., 2011; Lopez-Martinez et al., 2009; Mendoza-Díaz et al., 2012; Pedreschi \& Cisneros-Zevallos, 2006). For the purpose of this study, we obtained a wide range of colored corns by crossing waxy and dent genotypes and collecting unique accessions. We then measured their antioxidant activity and the level of antioxidant compounds in order to analyze the correlation between antioxidant activity and phytochemicals. Multivariate analysis was used to visualize the data for correlation as well.

\section{Method}

\subsection{Sample Preparation and Extraction}

Pictures of Korean colored corn samples from Dr. Soon Kwon Kim's lab in Kyungpook National University and their color phenotype are presented in Figure 1. Corn samples were ground enough to pass though a 100-mesh screen. Fifty grams of each of the dried corns were finely ground and mixed into $300 \mathrm{~mL}$ of $60 \%$ methanol containing $1 \% \mathrm{HCl}$. In order to increase the yield of phenol and flavonoid, the mixture was boiled at $50^{\circ} \mathrm{C}$ for 1 h. The extracts obtained were used for the determination of the total phenol content and total flavonoid content.

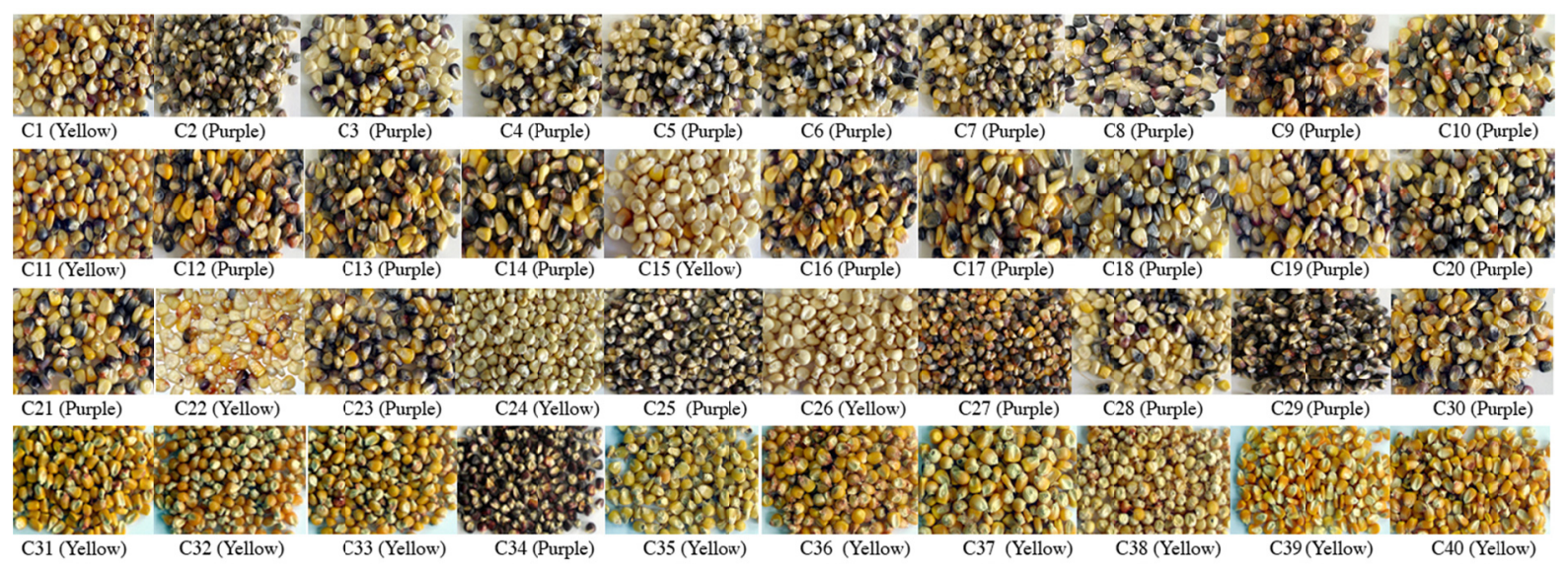

Figure 1. Sample images and color phenotype for principal component analysis

\subsection{Determination of Total Anthocyanin Content (TAC)}

Total anthocyanin was determined using the spectrophotometric method adapted from that of Abdel-Aal and Huel (1999). A $0.5 \mathrm{~g}$ corn sample was weighed in a $50 \mathrm{~mL}$ centrifuge tube and $10 \mathrm{~mL}$ of chilled, acidified methanol (95\% methanol and $1 \mathrm{~N} \mathrm{HCl} \mathrm{85:15,v/v)} \mathrm{was} \mathrm{added.} \mathrm{The} \mathrm{tube} \mathrm{was} \mathrm{flushed} \mathrm{with} \mathrm{nitrogen} \mathrm{gas,} \mathrm{agitated}$ for $30 \mathrm{~min}$, and centrifuged at $3000 \mathrm{~g}$ for $10 \mathrm{~min}$ before the supernatant was collected. Absorbance of the solution was measured immediately at $535 \mathrm{~nm}$ and corrected for background absorbance at $700 \mathrm{~nm}$ (due to turbidity). Anthocyanin content was calculated by $\mathrm{C}=[(\mathrm{A} 535 \mathrm{~nm}-\mathrm{A} 700 \mathrm{~nm}) / \varepsilon] \times($ total vol of extract $) \times \mathrm{MW} \times(1 /$ sample wt) where $\mathrm{C}$ is the concentration of total anthocyanin $(\mathrm{mg}$ of cyanidin 3-glucoside equivalents per $g$ of sample). $\varepsilon$ is the molar absorptivity (cyanidin-3-glucoside $=25965 / \mathrm{cm} / \mathrm{M}$ ), and $\mathrm{MW}$ is the molecular weight of cyanidin-3-glucoside, 449.2 .

\subsection{Determination of Total Phenol Content (TPC)}

Total phenol content was measured by the published method (Isabelle, Lee, Ong, Liu, \& Huang, 2008). The assay conditions were as follows: $10 \mu \mathrm{L}$ of sample was added to $160 \mu \mathrm{L}$ of 0.2 Folin-Ciocalteu's phenol reagent (Sigma, St. Louis, MO, USA) in 96 wells. After $3 \mathrm{~min}, 30 \mu \mathrm{L}$ of saturated sodium carbonate solution was added to the mixture and then incubated at room temperature for $30 \mathrm{~min}$. Absorbance of the resulting mixture was 
measured at $760 \mathrm{~nm}$. The total phenol contents were calculated using a standard curve with different concentrations of gallic acid ranging from $62.5-1000 \mu \mathrm{g} / \mathrm{mL}$. Results were expressed in $\mu \mathrm{g} / \mathrm{mL}$ of gallic acid (Sigma) equivalents (GAE).

\subsection{Determination of Total Flavonoid Content (TFC)}

Total flavonoid content was measured by the Abeysinghe et al. (2007) method with minor modifications using naringin (Sigma) as the standard. Each $10 \mu \mathrm{L}$ sample was added to one of 96 wells. $180 \mu \mathrm{L}$ of $90 \%$ diethylene glycol (Sigma) was added into the microplate agitater and shaken for 3 min (Titamax 101, Heidolph, Schwabach, Germany). $10 \mu \mathrm{L}$ of $1 \mathrm{~N} \mathrm{NaOH}$ was mixed into each of the sample wells. The absorbance was measured at 427 $\mathrm{nm}$ after $1 \mathrm{~h}$. A standard curve was carried out with naringin standard solutions in concentrations ranging from $62.5-1000 \mu \mathrm{g} / \mathrm{mL}$. Results were expressed in $\mu \mathrm{g} / \mathrm{mL}$ of naringin equivalents.

\subsection{Determination of Total Carotenoid Content (TCC)}

The carotenoid extraction procedure involved the employment of a method established by Kurilich and Juvik (1999). Six hundred $\mathrm{mg}$ of ground corn samples were mixed with a $5 \mathrm{~min}$ ethanol precipitation $(6 \mathrm{~mL}$ of ethanol containing $0.1 \%$ butylated hydroxytoluene (BHT, Sigma)) in an $85^{\circ} \mathrm{C}$ water bath before being subjected to a 10 min saponification with $120 \mu \mathrm{L}$ of $80 \%$ potassium hydroxide $(\mathrm{KOH})$. All samples were vortexed once during saponification. Upon removal they were immediately placed in an ice bath where $3 \mathrm{~mL}$ of cold deionized distilled water was added. Each sample then received $3 \mathrm{~mL}$ of hexane, was vortexed, and then was centrifuged for $10 \mathrm{~min}$ at $1200 \mathrm{~g}$. The upper layer was pipetted into a separate test tube and total carotenoid content was determined using formula (Rodriguez-Amaya \& Kimura, 2004):

Absorbance at $450 \mathrm{~nm} \times$ volume $(\mathrm{mL}) \times 10^{4} /[2500$ (absorption coefficient) $\times$ sample weight $(\mathrm{g})]$

\subsection{Determination of the Antioxidant Activity}

The 2,2'-azinobis (3-ethylbenzothiazoline-6-sulfonic acid) diammonium salt (ABTS) assay was measured as described by previous study (Ku et al., 2010). $7 \mathrm{mM}$ of ABTS ammonium was dissolved in water and treated with $2.45 \mathrm{mM}$ of potassium persulfate, and the mixture was then allowed to stand at room temperature for 12-16 $\mathrm{h}$ to obtain a dark blue solution. This solution was diluted with ethanol until the absorbance reached 0.7 at 734 nm. $190 \mu \mathrm{L}$ of resulting solution was mixed with $10 \mu \mathrm{L}$ of sample. The absorbance was read at room temperature. ABTS activity was expressed as a percentage of scavenging activity compared to the control. The antioxidant capacity of samples was also estimated in another assay according to the procedure described by previous study (Ku et al., 2010). Briefly explained, $190 \mu \mathrm{L}$ of Ferric Reducing/Antioxidant Power (FRAP) reagent, freshly prepared and kept at room temperature, was mixed with $10 \mu \mathrm{L}$ of test sample, extract solutions as appropriate for the reagent blank. The absorbance was measured at $593 \mathrm{~nm}$ after 4 min using a spectrophotometer.The FRAP reagent contained $2.5 \mathrm{~mL}$ of a $10 \mathrm{mmol} / \mathrm{L}$ 2,4,6-tripyridyl-s-triazine (Sigma) solution in $40 \mathrm{mmol} / \mathrm{L} \mathrm{HCl}$ plus 2.5 $\mathrm{mL}$ of $20 \mathrm{mmol} / \mathrm{L} \mathrm{FeCl} \cdot 6 \mathrm{H}_{2} \mathrm{O}$ and $25 \mathrm{~mL}$ of $0.3 \mathrm{~mol} / \mathrm{L}$ acetate buffer, $\mathrm{pH} 3.6$. The FRAP values were calculated from a standard curve of Trolox concentrations ranging from $62.5-500 \mu \mathrm{mol} / \mathrm{L}$.

\subsection{Multivariate Analysis}

Multivariate analysis was performed using MetaboAnalyst (Xia, Psychogios, Young, \& Wishart, 2009) to create a principal component analysis (PCA) biplot. The unit scaling column-wise normalization was used before the analysis. In order to achieve clustering, ward and pearson algorithms were used for clustering and distance measure. Pearson's correlation analysis was conducted using the SAS 9.1 software (SAS institute Inc., Cary, $\mathrm{NC})$.

\section{Results and Discussion}

\subsection{Total Anthocyanin Content (TAC)}

The TAC varied significantly among samples ranging from 0 to $90 \mathrm{mg} / 100 \mathrm{~g}$ of dry corn $\left(\mathrm{F}_{39,80}=1118, \mathrm{p}<0.001\right)$. The average TAC was $30 \mathrm{mg} / 100 \mathrm{~g}$ of dry corn (Table 1). C29 showed the highest TAC. The coefficient of variation (CV) of TAC was $85.0 \%$ (Table 1). We assume that significant variation of TAC can contribute to the antioxidant activity of Korean colored corn because the previous studies have reported that anthocyanins could considerably contribute to the antioxidant activity in corns, wine and the common fig (Žilić, Serpen, Akıllıŏlu, Gökmen, \& Vančetović, 2012; Rivero-Perez, Muniz, \& Gonzalez-Sanjose, 2008; Solomon et al., 2006). Recently, it was reported that total anthocyanin contents of anthocyanin-rich colored corn genotypes ranged from 2.5 to 696 mg cyaniding 3-glucoside equivalent $/ \mathrm{kg} \mathrm{d.m.} \mathrm{with} \mathrm{cyaniding} \mathrm{3-glucoside} \mathrm{as} \mathrm{the} \mathrm{most} \mathrm{abundant} \mathrm{form} \mathrm{(Žilić} \mathrm{et} \mathrm{al.,}$ 2012). 
Table 1. Antioxidant compounds and antioxidant activity of Korean colored corn

\begin{tabular}{|c|c|c|c|c|c|c|c|c|}
\hline & Pedigree & Kernel phenotype $^{\mathrm{a}}$ & $\mathrm{TAC}^{\mathrm{b}}$ & $\mathrm{TPC}^{\mathrm{c}}$ & $\mathrm{TFC}^{\mathrm{d}}$ & $\mathrm{TCC}^{\mathrm{e}}$ & $\operatorname{ABTS}^{\mathrm{f}}$ & FRAP $^{f}$ \\
\hline $\mathrm{C} 1$ & $601-309$ & Yellow and purple (Y) & $34 \pm 2$ & $289 \pm 14$ & $224 \pm 29$ & $11 \pm 4$ & $10.3 \pm 0.7$ & $7.7 \pm 0.7$ \\
\hline $\mathrm{C} 2$ & $601-321$ & Yellow and & $44 \pm 1$ & $362 \pm 17$ & $272 \pm 43$ & $63 \pm 2$ & $12.6 \pm 0.3$ & $9.6 \pm 0.6$ \\
\hline $\mathrm{C} 3$ & $602-117$ & Yellow and & $20 \pm 1$ & $311 \pm 40$ & $202 \pm 30$ & $103 \pm 2$ & $9.7 \pm 0.2$ & $7.4 \pm 0.5$ \\
\hline $\mathrm{C} 4$ & $602-304$ & Yellow : & $30 \pm 1$ & $361 \pm 47$ & $256 \pm 36$ & $89 \pm 12$ & $10.8 \pm 0.3$ & $9.4 \pm 0.5$ \\
\hline $\mathrm{C} 5$ & $602-305$ & Yellow and pu & $43 \pm 1$ & $362 \pm 44$ & $282 \pm 21$ & $63 \pm 23$ & $11.8 \pm 0.3$ & $9.5 \pm 0.7$ \\
\hline C6 & $602-306$ & Yellow and purple (P) & $30 \pm 2$ & $372 \pm 46$ & $264 \pm 23$ & $99 \pm 16$ & $10.0 \pm 1.2$ & $9.9 \pm 0.4$ \\
\hline C7 & $602-307$ & Yellow and purple (P) & $43 \pm 1$ & $325 \pm 46$ & $254 \pm 25$ & $92 \pm 4$ & $11.3 \pm 0.4$ & $8.3 \pm 0.6$ \\
\hline $\mathrm{C} 8$ & $602-312$ & Yellow and purp & $38 \pm 1$ & $300 \pm 32$ & $218 \pm 19$ & $133 \pm 9$ & $12.0 \pm 0.5$ & $8.1 \pm 0.4$ \\
\hline C9 & $604-117$ & Yellow and & $34 \pm 1$ & $384 \pm 58$ & $307 \pm 30$ & $164 \pm 4$ & $13.3 \pm 0.4$ & $11.6 \pm 0.9$ \\
\hline $\mathrm{C} 10$ & $604-118$ & Yellow and & $53 \pm 3$ & $421 \pm 65$ & $366 \pm 18$ & $240 \pm 8$ & $12.8 \pm 0.4$ & $12.2 \pm 0.8$ \\
\hline $\mathrm{C} 11$ & $604-122$ & Yellow (Y) & $11 \pm 0$ & $428 \pm 56$ & $307 \pm 26$ & $564 \pm 11$ & $12.0 \pm 0.1$ & $12.6 \pm 0.2$ \\
\hline $\mathrm{C} 12$ & 604-202 & Yellow and purple $(\mathrm{P})$ & $51 \pm 2$ & $427 \pm 38$ & $300 \pm 34$ & $237 \pm 18$ & $12.5 \pm 0.3$ & $10.1 \pm 0.7$ \\
\hline $\mathrm{C} 13$ & 604-204 & Yellow and purple $(\mathrm{P})$ & $51 \pm 3$ & $411 \pm 36$ & $281 \pm 23$ & $128 \pm 14$ & $12.7 \pm 0.4$ & $9.8 \pm 0.5$ \\
\hline C14 & $604-205$ & Yellow & $47 \pm 0$ & $436 \pm 63$ & $292 \pm$ & $139=$ & .5 & $9.5 \pm 0.4$ \\
\hline $\mathrm{C} 15$ & $604-208$ & Light yellow (Y) & $0 \pm 0$ & $369 \pm 12$ & $287 \pm 23$ & $16 \pm 17$ & $10.3 \pm 0.3$ & $8.8 \pm 0.7$ \\
\hline $\mathrm{C} 16$ & $604-212$ & Purpl & $57 \pm 1$ & $377 \pm 19$ & $275 \pm 14$ & $75 \pm 5$ & $12.6 \pm 0.3$ & $9.5 \pm 0.8$ \\
\hline $\mathrm{C} 17$ & 603-109 & Yellow and purp & $49 \pm 2$ & $337 \pm 56$ & $256 \pm 18$ & $95 \pm 5$ & $11.9 \pm 0.4$ & $9.0 \pm 0.9$ \\
\hline $\mathrm{C} 18$ & $603-115$ & Yellow and & $19 \pm 0$ & $320 \pm 50$ & $240 \pm 14$ & $23 \pm 2$ & $11.3 \pm 0.6$ & $9.2 \pm 0.4$ \\
\hline C19 & $603-214$ & Yellow anc & $36 \pm 1$ & $338 \pm 42$ & $261 \pm 24$ & $32 \pm 4$ & $10.9 \pm 0.4$ & $8.7 \pm 0.5$ \\
\hline $\mathrm{C} 20$ & 603-309 & Yellow an & $37 \pm 1$ & $410 \pm 32$ & $307 \pm 37$ & $84 \pm 4$ & $12.3 \pm 0.2$ & $11.0 \pm 0.6$ \\
\hline $\mathrm{C} 21$ & $603-310$ & Yellow an & $36 \pm 1$ & $400 \pm 37$ & $247 \pm 25$ & $115 \pm 6$ & $12.5 \pm 0.5$ & $9.9 \pm 0.3$ \\
\hline $\mathrm{C} 22$ & $603-314$ & Yell & $2 \pm 0$ & $390 \pm 17$ & $277 \pm 24$ & $41 \pm 6$ & $10.1 \pm 0.6$ & $9.4 \pm 0.4$ \\
\hline $\mathrm{C} 23$ & $603-316$ & Yellow anc & $21 \pm 1$ & $347 \pm 18$ & $260 \pm 3$ & $85 \pm 6$ & $10.6 \pm 0.5$ & $8.4 \pm 0.5$ \\
\hline $\mathrm{C} 24$ & $w x-3$ & Light yellow (Y) & $1 \pm 0$ & $467 \pm 39$ & $394 \pm 32$ & $20 \pm 4$ & $11.0 \pm 0.4$ & $12.7 \pm 0.8$ \\
\hline $\mathrm{C} 25$ & Black waxy & Purple (P) & $68 \pm 1$ & $315 \pm 43$ & $251 \pm 33$ & $45 \pm 2$ & $11.6 \pm 0.8$ & $8.7 \pm 0.5$ \\
\hline $\mathrm{C} 26$ & White waxy & Light yellow (Y) & $5 \pm 0$ & $303 \pm 39$ & $297 \pm 28$ & $57 \pm 9$ & $9.7 \pm 0.2$ & $9.6 \pm 0.7$ \\
\hline $\mathrm{C} 27$ & $601-110$ & Purple (P) & $63 \pm 2$ & $296 \pm 31$ & $220 \pm 21$ & $108 \pm 7$ & $10.6 \pm 0.8$ & $7.1 \pm 0.6$ \\
\hline $\mathrm{C} 28$ & $601-313$ & Purple (P) & $80 \pm 3$ & $385 \pm 32$ & $301 \pm 31$ & $44 \pm 4$ & $12.5 \pm 0.4$ & $9.9 \pm 0.7$ \\
\hline $\mathrm{C} 29$ & $601-320$ & Purple (P) & $90 \pm 1$ & $394 \pm 30$ & $515 \pm 47$ & $29 \pm 6$ & $14.4 \pm 0.4$ & $10.2 \pm 0.6$ \\
\hline $\mathrm{C} 30$ & $601-322$ & Yellow and purple $(\mathrm{P})$ & $28 \pm 1$ & $319 \pm 27$ & $241 \pm 25$ & $323 \pm 15$ & $11.0 \pm 0.4$ & $7.7 \pm 0.4$ \\
\hline $\mathrm{C} 31$ & $70 \mathrm{~B}$ & Yellow (Y) & $1 \pm 0$ & $290 \pm 23$ & $180 \pm 14$ & $316 \pm 7$ & $9.2 \pm 0.6$ & $8.2 \pm 0.4$ \\
\hline C32 & NKE5 & & $6 \pm 0$ & $275 \pm 20$ & $203 \pm 17$ & $361 \pm 10$ & $8.6 \pm 1.1$ & $7.7 \pm 0.3$ \\
\hline $\mathrm{C} 33$ & NKE3 & & $1 \pm 0$ & $308 \pm 19$ & $238 \pm 19$ & $235 \pm 24$ & $9.9 \pm 0.5$ & $8.8 \pm 0.5$ \\
\hline $\mathrm{C} 34$ & Cheongdo & Purple (P) & $85 \pm 4$ & $352 \pm 21$ & $255 \pm 19$ & $44 \pm 22$ & $12.8 \pm 0.5$ & $8.4 \pm 0.2$ \\
\hline $\mathrm{C} 35$ & 69B1 & Yellow (Y) & $5 \pm 0$ & $395 \pm 34$ & $325 \pm 29$ & $49 \pm 5$ & $9.4 \pm 0.4$ & $10.1 \pm 0.3$ \\
\hline $\mathrm{C} 36$ & 70A1 & & $1 \pm 0$ & $307 \pm 32$ & $194 \pm 19$ & $335 \pm 6$ & $9.1 \pm 0.5$ & $6.8 \pm 0.2$ \\
\hline C37 & $72 \mathrm{~A}$ & & $1 \pm 0$ & $290 \pm 44$ & $189 \pm 14$ & $241 \pm 13$ & $8.7 \pm 0.8$ & $6.4 \pm 0.3$ \\
\hline C38 & wx-7-sh8-c & Yellow (Y) & $1 \pm 0$ & $395 \pm 50$ & $313 \pm 58$ & $136 \pm 0$ & $12.8 \pm 0.3$ & $10.5 \pm 0.5$ \\
\hline C39 & 69B1-P45 & Yellow (Y) & $0 \pm 0$ & $334 \pm 56$ & $269 \pm 16$ & $257 \pm 8$ & $10.1 \pm 0.2$ & $10.4 \pm 0.6$ \\
\hline $\mathrm{C} 40$ & $66 \mathrm{~B} 2$ & Yellow (Y) & $0 \pm 0$ & $223 \pm 17$ & $178 \pm 18$ & $27 \pm 6$ & $5.1 \pm 0.9$ & $6.7 \pm 0.3$ \\
\hline
\end{tabular}




$\begin{array}{ccccccc}\text { Mean } \pm \mathrm{SD} & 30 \pm 26 & 353 \pm 53 & 270 \pm 62 & 135 \pm 119 & 11 \pm 2 & 9 \pm 2 \\ \text { Max } & 90 & 467 & 515 & 564 & 14 & 12.7 \\ \text { Min } & 0 & 223 & 178 & 16 & 5 & 6.4 \\ \text { CV (\%) } & 85.0 & 15.0 & 22.8 & 87.8 & 15.5 & 16.3 \\ \text { F-test } & \mathrm{F}_{39,80} & \mathrm{~F}_{39,120} & \mathrm{~F}_{39,120} & \mathrm{~F}_{39,80} & \mathrm{~F}_{39,120} & \mathrm{~F}_{39,120} \\ & =1118^{* * *} & =7.4^{* * *} & =15.2^{* * *} & =415^{* * *} & =11.2^{* * *} & =30.0^{* * *}\end{array}$

\footnotetext{
${ }^{a}$ Kernel phenotype, letter in parenthesis indicate $\mathrm{Y}=$ yellow and $\mathrm{P}=$ purple, respectively for principal component analysis. ${ }^{\mathrm{b}}$ The total anthocyanin content is expressed as milligrams of cyanidin-3-glucoside equivalent concentration per $100 \mathrm{~g}$ of dry corn. ${ }^{\mathrm{c}}$ Total phenol content is expressed as milligrams of gallic acid equivalent (GAE) concentration per $100 \mathrm{~g}$ of dry corn. ${ }^{\mathrm{d}}$ The total flavonoid content is expressed as milligrams of naringin equivalent (NE) concentration per gram of $100 \mathrm{~g}$ of dry corn. ${ }^{\mathrm{e}}$ The total carotenoid content is expressed as micrograms per $100 \mathrm{~g}$ of dry corn. ${ }^{\mathrm{f}} \mathrm{ABTS}$ radical scavenging activity and FRAP values were expressed as Trolox equivalent concentration millimols per $\mathrm{g}$ of dry corn. All are expressed as the mean $\pm \mathrm{SD}$ of three (TAC, TCC) or four replicates.
}

\subsection{Total Phenol Content (TPC)}

The TPC varied significantly among samples ranging from 223 to $467 \mathrm{mg} / 100 \mathrm{~g}$ of dry corn $\left(\mathrm{F}_{39,120}=7.4^{* * *}\right.$, $\mathrm{p}<0.001$ ). The average TPC was $353 \mathrm{mg} / 100 \mathrm{~g}$ of dry corn. The CV of TPC was $15.0 \%$ (Table 1 ). According to the previous study, TPC found in corn was significantly higher than in wheat, oats, and rice (Adom \& Liu, 2002). It has been reported that trans-ferulic acid was the predominant phenol compound derived from corn (Sosulski, Krygier, \& Hogge, 1982).

\subsection{Total Flavonoid Content (TFC)}

The TFC varied significantly among samples ranging from 178 to $515 \mathrm{mg} / 100 \mathrm{~g}$ of dry corn $\left(\mathrm{F}_{39,120}=15.2^{* * *}\right.$, $\mathrm{p}<0.001$ ). The average level of TFC was $270 \mathrm{mg} / 100 \mathrm{~g}$ of dry corn (Table 1 ). The CV of TFC was $22.8 \%$ (Table 1). Some flavonoids are known as cancer chemopreventive agents that induce quinone reductase (Moon et al., 2006). Flavonoids also have strong antioxidant properties (Kim \& Lee, 2004). C29, having the highest content of TFC, would be a good material for corn which promotes good health.

\subsection{Total Carotenoid Content (TCC)}

There was significant variation of TCC among the samples $\left(\mathrm{F}_{39,80}=415^{* * *}, \mathrm{p}<0.001\right)$. The TCC ranged from 16 to $564 \mu \mathrm{g} / 100 \mathrm{~g}$ of dry corn. The average level of TCC was $135 \mu \mathrm{g} / 100 \mathrm{~g}$ of dry corn. The CV of TCC was $87.8 \%$ (Table 1). Unlike other secondary compounds in corn, the function of carotenoids in the human body is crucial because it is converted to and acts as Vitamin A. It is an important compound for preventing degenerative eye diseases (Kurilich \& Juvik, 1999).

\subsection{Determination of the Antioxidant Activity Using ABTS and FRAP}

The ABTS result did not demonstrate as great of a variation as anthocyanin or carotenoid contents but was significantly different among samples $\left(\mathrm{F}_{39,120}=11.2^{* * *}, \mathrm{p}<0.001\right)$. The CV of ABTS was $15.5 \%$ (Table 1). C29 displayed the highest level of ABTS scavenging activity (Table 1). Interestingly, C29 was also the compound with the highest levels of TAC and TFC. The result of FRAP, like the ABTS result, did not show much variation compared to anthocyanin or carotenoid contents but was significantly different among samples $\left(\mathrm{F}_{39,120}=30.0^{* * *}\right.$, $\mathrm{p}<0.001$ ). The CV of FRAP was $16.3 \%$ (Table 1). C24 showed the highest FRAP antioxidant activity and contains the highest level of TPC (Table 1). Moreover, the overall rank of the FRAP assay is not the same as the ABTS assay. This indicates that the ABTS radical scavenging based assay is different from FRAP assay although both assays are based on electron transfer-based antioxidant assay (Huang, Ou, \& Prior, 2005).

\subsection{Correlation Analysis}

There were several meaningful correlations (Table 2). First of all, the ABTS assay correlated with FRAP, TAC, TPC, TFC but not TCC. Among them, that relationship between ABTS and TAC was the strongest correlation $(r=0.721, p<0.01)$ as previously observed in red carrot and pigmented Creole maize races (Leja et al., 2013; Mendoza-Díaz et al., 2012). Žilić et al. (2012) reported singificant correlation between insouble bound ferulic acid and ABTS assay from colored corns. The FRAP assay correlated TPC and TFC, but not TAC and TCC. The lack of correlation between TCC and antioxidant activities may indicate that the antioxidant assays employed 
here utilize inappropriate solvent extraction systems for non-polar compounds such as carotenoids. It is worth noting that TAC correlated only with ABTS assay. This suggests that an antioxidant assay such as ABTS may react differently with different classes of compounds even though both ABTS and FRAP assays are electron transfer-based antioxidant assays (Huang et al., 2005). The correlation between TAC and TFC $(r=0.343, p=0.06)$ is natural because anthocyanins are a subclass of flavonoid. Also, it is natural that TFC correlated with TPC $(r=0.730, p<0.01)$ because flavonoid is one class of phenol compound. TCC weakly correlated with TAC $(r=-0.386, p=0.03)$ and TFC $(r=-0.322, p=0.08)$ but this may be due to chance because their biosynthesis occurs in separate pathways (phenlypropanoid and terpenoid, respectively).

Table 2. Correlation coefficients between bioactivities and functional constituents

\begin{tabular}{llllll}
\hline Variable & 1 & 2 & 3 & 4 & 5 \\
\hline 1. ABTS & 1 & & & & \\
2. FRAP & $0.553^{* *}$ & 1 & & \\
3. Total anthocyanin content & $0.721^{* *}$ & $0.096^{\mathrm{ns}}$ & 1 & & \\
4. Total phenol content & $0.640^{* *}$ & $0.840^{* *}$ & $0.241^{\mathrm{ns}}$ & 1 & \\
5. Total flavonoid content & $0.613^{* *}$ & $0.746^{* *}$ & $0.343^{*}$ & $0.730^{* *}$ & 1 \\
6. Total carotenoid content & $-0.222^{\mathrm{ns}}$ & $-0.075^{\mathrm{ns}}$ & $-0.386^{*}$ & $0.222^{\mathrm{ns}}$ & $-0.322^{\mathrm{ns}}$ \\
\hline
\end{tabular}

Pearson's correlation analysis was conducted using averaged values of each variable $(n=40)$.

${ }^{* * * *}, \mathrm{~ns}$ indicate that significant at $p=0.01,0.05$, and non-significant, respectively.

\subsection{Principal Component Analysis (PCA)}

The yellow corns and corns containing purple are mainly separated by components 1,2 , and 3 . The first, second, and third component explained $55.4 \%, 21.9 \%$, and $13.6 \%$ of the overall variation respectively (Figure $2 \mathrm{~A}$ ). This indicates that the phenotypes of corn have a large influence on the chemical composition and antioxidant activity of corn. High phenol and flavonoid groups were separated by PC1 and high anthocyanin and carotenoid groups were separated by PC2 on the biplot (Figrue 2B). The groups with high anthocyanin content (C25, C27, C28, C34), high carotenoid content (C11, C31, C32, C33, C36, C37, C40), and high phenol and flavonoid content (C9, $\mathrm{C} 10, \mathrm{C} 11, \mathrm{C} 12, \mathrm{C} 14, \mathrm{C} 20, \mathrm{C} 24, \mathrm{C} 29)$ were easily visualized on the biplot (Figure 2B). On the biplot, TCC and TAC segregate in opposite directions, meaning these two factors are negatively correlated (Table 2). The angle between FRAP and TPC is very small, indicating that two factors are positively correlated (Table 2). This correlation information is consistent with Table 2. PCA analysis was successfully utilized by Lopez-Galilea, de Pena and Cid (2008) to easily visualize the antioxidant and volatile compounds information of the samples and to successfully pinpoint antioxidant compounds of roasted coffee. Another study also used PCA techniques to describe the antioxidant and polyphenol content of various lettuces (Llorach, Martinez-Sanchez, Tomas-Barberan, Gil, \& Ferreres, 2008). The PCA analysis was also very useful in this study for visualizing and allowing much information to be taken in. Moreover, this multivariate analysis has several advantages: coping with missing data, handing many variables and few observations (Eriksson, 2006). 

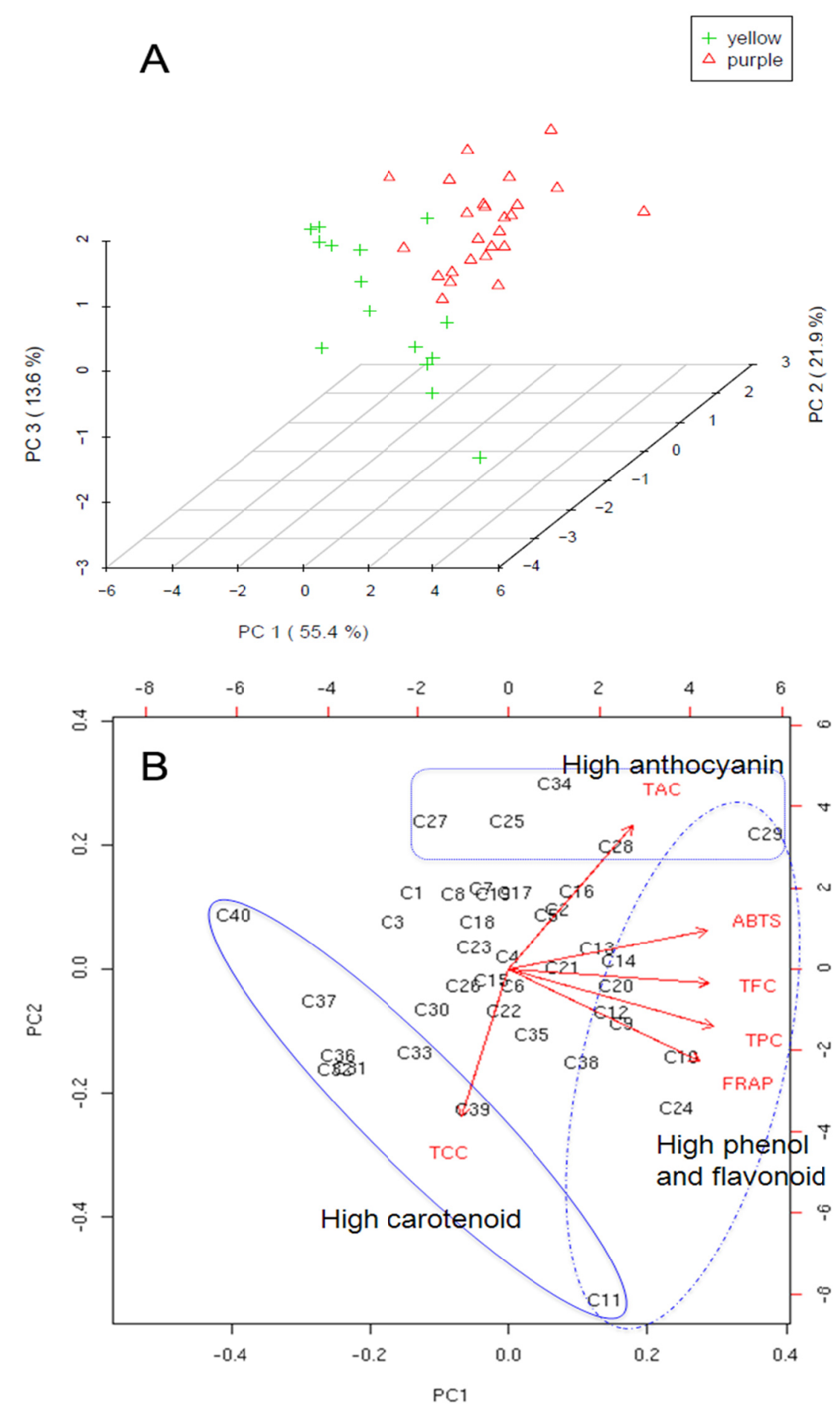

Figure 2. Principal component analysis score plot (A) and biplot (B).

\section{Conclusion}

Potential antioxidant compounds in Korean colored corns were phenol compounds, including anthocyanins and flavonoids. Anthocyanins from Korean colored corns correlated with the ABTS assay while their flavonoids correlated with the FRAP assay. Anthocyanins and carotenoids showed a large variation as compared to other compounds. Especially, anthocyanins are good target to increase antioxidant activity in colored corns because it had high variation and strong correlation to antioxidant capacity while flavonoids and phenols had less variation 
and carotenoids had less correlation with antioxidant capacity. Multivariate analysis also showed same result with the correlation analysis but it allows us to get a lot of information at a glance.

\section{References}

Abdel-Aal, E. S. M., \& Hucl, P. (1999). A rapid method for quantifying total anthocyanins in blue aleurone and purple pericarp wheats. Cereal Chem, 76(3), 350-354. http://dx.doi.org/10.1094/CCHEM.1999.76.3.350

Abeysinghe, D. C., Li, X., Sun, C., Zhang, W., Zhou, C., \& Chen, K. (2007). Bioactive compounds and antioxidant capacities in different edible tissues of citrus fruit of four species. Food Chem, 104(4), 1338-1344. http://dx.doi.org/10.1016/j.foodchem.2007.01.047

Adom, K. K., \& Liu, R. H. (2002). Antioxidant activity of grains. J Agric Food Chem, 50(21), $6182-6187$. http://dx.doi.org/10.1021/jf0205099

Cevallos-Casals, B. A., \& Cisneros-Zevallos, L. (2004). Stability of anthocyanin-based aqueous extracts of Andean purple corn and red-fleshed sweet potato compared to synthetic and natural colorants. Food Chem, 86(1), 69-77. http://dx.doi.org/10.1016/j.foodchem.2003.08.011

Dewanto, V., Wu, X., \& Liu, R. H. (2002). Processed sweet corn has higher antioxidant activity. J Agric Food Chem, 50(17), 4959-4964. http://dx.doi.org/10.1021/jf0255937

Huang, D., Ou, B., \& Prior, R. L. (2005). The chemistry behind antioxidant capacity assays. J Agric Food Chem, 53(6), 1841-1856. http://dx.doi.org/10.1021/jf030723c

Isabelle, M., Lee, B. L., Ong, C. N., Liu, X., \& Huang, D. (2008). Peroxyl radical scavenging capacity, polyphenolics, and lipophilic antioxidant profiles of mulberry fruits cultivated in southern China. J Agric Food Chem, 56(20), 9410-9416. http://dx.doi.org/10.1021/jf801527a

Kim, D. O., \& Lee, C. Y. (2004). Comprehensive study on vitamin C equivalent antioxidant capacity (VCEAC) of various polyphenolics in scavenging a free radical and its structural relationship. Crit Rev Food Sci Nutr, 44(4), 253-273. http://dx.doi.org/10.1080/10408690490464960

Ku, K. M., Choi, J. N., Kim, J., Kim, J. K., Yoo, L. G., Lee, S. J. \& Lee, C. H. (2010). Metabolomics analysis reveals the compositional differences of shade grown tea (Camellia sinensis L.). J Agric Food Chem, 58(1), 418-426. http://dx.doi.org/10.1021/jf902929h

Kurilich, A. C., \& Juvik, J. A. (1999). Quantification of Carotenoid and Tocopherol Antioxidants in Zea mays. $J$ Agric Food Chem, 47(5), 1948-1955. http://dx.doi.org/10.1021/jf981029d

Eriksson, E. Kettaneh-Wold, J., N., \& J. Trygg. (2006). Multivariate and Megavariate Data Analysis Basic Principles and Applications Part I: Basic Principles and Applications. Umeå, Sweden: Umetrics Academy.

Laranjinha, J. o. A. N., Almeida, L. M., \& Madeira, V. M. C. (1994). Reactivity of dietary phenolic acids with peroxyl radicals: Antioxidant activity upon low density lipoprotein peroxidation. Biochemical Pharmacology, 48(3), 487-494. http://dx.doi.org/10.1016/0006-2952(94)90278-X

Lee, K. W., \& Lee, H. J. (2006). The roles of polyphenols in cancer chemoprevention. Biofactors, 26(2), $105-121$.

Leja, M., Kamińska, I., Kramer, M., Maksylewicz-Kaul, A., Kammerer, D., Carle, R., \& Baranski, R. (2013). The content of phenolic compounds and radical scavenging activity varies with carrot origin and root color. Plant Foods Hum Nutr, 68(2), 163-170. http://dx.doi.org/10.1007/s11130-013-0351-3

Li, W., Wei, C. V., White, P. J., \& Beta, T. (2007). High-amylose corn exhibits better antioxidant activity than typical and waxy genotypes. J Agric Food Chem, 55(2), 291-298. http://dx.doi.org/10.1021/jf0622432

Liu, R. H. (2007). Whole grain phytochemicals and health. $J$ Cereal Sci, 46(3), $207-219$. http://dx.doi.org/10.1016/j.jcs.2007.06.010

Llorach, R., Martinez-Sanchez, A., Tomas-Barberan, F. A., Gil, M. I., \& Ferreres, F. (2008). Characterisation of polyphenols and antioxidant properties of five lettuce varieties and escarole. Food Chem, 108(3), 1028-1038. http://dx.doi.org/10.1016/J.Foodchem.2007.11.032

Lopez-Galilea, I., de Pena, M. P., \& Cid, C. (2008). Application of multivariate analysis to investigate potential antioxidants in conventional and torrefacto roasted coffee. Eur Food Res Technol, 227(1), 141-149. http://dx.doi.org/10.1007/S00217-007-0703-Z

Lopez-Martinez, L. X., Parkin, K., \& Garcia, H. (2011). Phase II-inducing, polyphenols content and antioxidant capacity of corn (Zea mays L.) from phenotypes of white, blue, red and purple colors processed into masa and tortillas. Plant Foods Hum Nutr, 66(1), 41-47. http://dx.doi.org/10.1007/s11130-011-0210-z 
Lopez-Martinez, L. X., Oliart-Ros, R. M., Valerio-Alfaro, G., Lee, C.-H., Parkin, K. L., \& Garcia, H. S. (2009). Antioxidant activity, phenolic compounds and anthocyanins content of eighteen strains of Mexican maize. Lwt-Food Sci Technol, 42(6), 1187-1192. http://dx.doi.org/10.1016/j.lwt.2008.10.010

Mendoza-Díaz, S., Ortiz-Valerio, M. D., Castaño-Tostado, E., Figueroa-Cárdenas, J., Reynoso-Camacho, R., Ramos-Gómez, M., \& Guadalupe Loarca-Piña, G. (2012). Antioxidant capacity and antimutagenic activity of anthocyanin and carotenoid extracts from nixtamalized pigmented Creole maize races (Zea mays L.). Plant Foods Hum Nutr, 67(4), 442-449. http://dx.doi.org/10.1007/s11130-012-0326-9

Moon, Y. J., Wang, X., \& Morris, M. E. (2006). Dietary flavonoids: Effects on xenobiotic and carcinogen metabolism. Toxicol in Vitro, 20(2), 187-210. http://dx.doi.org/10.1016/j.tiv.2005.06.048.

Pedreschi, R., \& Cisneros-Zevallos, L. (2006). Antimutagenic and antioxidant properties of phenolic fractions from Andean purple corn (Zea mays L.). J Agric Food Chem, 54(13), 4557-4567. http://dx.doi.org/10.1021/jf0531050

Poulsen, H. E., Prieme, H., \& Loft, S. (1998). Role of oxidative DNA damage in cancer initiation and promotion. Eur J Cancer Prev, 7(1), 9-16.

Rivero-Perez, M. D., Muniz, P., \& Gonzalez-Sanjose, M. L. (2008). Contribution of anthocyanin fraction to the antioxidant properties of wine. Food Chem Toxicol, 46(8), 2815-2822. http://dx.doi.org/10.1016/j.fct.2008.05.014

Rodriguez-Amaya, D. B., \& Kimura, M. (2004). HarvestPlus Handbook for Carotenoid Analysis. International Food Policy Research Institute (IFPRI).

Solomon, A., Golubowicz, S., Yablowicz, Z., Grossman, S., Bergman, M., Gottlieb, H. E., \& Flaishman, M. A. (2006). Antioxidant activities and anthocyanin content of fresh fruits of common fig (Ficus carica L.). $J$ Agric Food Chem, 54(20), 7717-7723. http://dx.doi.org/10.1021/jf060497h

Sosulski, F., Krygier, K., \& Hogge, L. (1982). Free, Esterified, and insouluble-bound phenolic-acids. 3. composition of phenolic-acids in cereal and potato flours. J Agric Food Chem, 30(2), 337-340. http://dx.doi.org/10.1021/jf00110a030

Valko, M., Izakovic, M., Mazur, M., Rhodes, C. J., \& Telser, J. (2004). Role of oxygen radicals in DNA damage and cancer incidence. Mol Cell Biochem, 266(1-2), 37-56. http://dx.doi.org/10.1023/B:Mcbi.0000049134.69131.89

Xia, J., Psychogios, N., Young, N., \& Wishart, D. S. (2009). MetaboAnalyst: a web server for metabolomic data analysis and interpretation. Nucleic Acids Res, 37(Web Server issue), W652-660. http://dx.doi.org/10.1093/nar/gkp356

Xu, J. G., Hu, Q. P., Wang, X. D., Luo, J. Y., Liu, Y., \& Tian, C. R. (2010). Changes in the main nutrients, phytochemicals, and antioxidant activity in yellow corn grain during maturation. J Agric Food Chem, 58(9), 5751-5756. http://dx.doi.org/10.1021/jf100364k

Žilić, S., Serpen, A., Akıllığlu, G., Gökmen, V., \& Vančetović, J. (2012). Phenolic compounds, carotenoids, anthocyanins, and antioxidant capacity of colored maize (Zea mays L.) kernels. J Agric Food Chem, 60(5), 1224-1231. http://dx.doi.org/10.1021/jf204367z

\section{Copyrights}

Copyright for this article is retained by the author(s), with first publication rights granted to the journal.

This is an open-access article distributed under the terms and conditions of the Creative Commons Attribution license (http://creativecommons.org/licenses/by/3.0/). 